Article

\title{
Public Transport Quality, Safety, and Perceived Accessibility
}

\author{
Margareta Friman *(1), Katrin Lättman (1) and Lars E. Olsson $(1)$ \\ CTF Service Research Center and Department of Social and Psychological Studies, Karlstad University, \\ SE-65188 Karlstad, Sweden; katrin.lattman@kau.se (K.L.); lars.e.olsson@kau.se (L.E.O.) \\ * Correspondence: margareta.friman@kau.se
}

Received: 1 April 2020; Accepted: 25 April 2020; Published: 27 April 2020

check for updates

\begin{abstract}
Service quality in public transport is proposed as a key determinant of perceived accessibility, the ease to live the life one wants with the help of the transport system, as low service quality may be a barrier for use, decreasing the ease to participate in daily activities. The first aim was to validate the direct relationship between public transport quality and perceived accessibility. Secondly, we analyzed the mediating role of safety perceptions to better explain the link between service quality and perceived accessibility. Public transport travelers $(n=4944)$ from five northern European cities were surveyed. Results from PLS-SEM modeling show that service quality has a significant and direct relationship with perceived accessibility, especially regarding functionality. An indirect relationship through travel safety perceptions was also observed, highlighting information and comfort as main drivers. High car use, low public transport use, increasing age, and being a woman were also associated with greater perceived accessibility. City comparisons yielded a number of significant differences. Our results contribute to the research literature by highlighting the importance of service quality in public transport for perceptions of accessibility in daily travel. In particular, we argue that functionality is the core attribute to focus on, and that attributes related to travel safety perceptions should be carefully considered when planning for sustainable transport.
\end{abstract}

Keywords: Public transport; service quality; perceived accessibility; traveler safety perception; sustainable travel

\section{Introduction}

The current focus on sustainable travel in Europe includes policies aiming at increasing the accessibility of public transport in order to make it an eligible substitute for the car in daily travel, especially in dense city areas. However, people are concerned about their safety on public transport. Potential safety hazards associated with public transport are injuries related to the infrastructure (e.g., stairs, escalators, platforms, ramps), violent crime (e.g., sexual offenses, knife attacks, terrorism, thefts), non-violent crime (e.g., anti-social behavior, vandalism, drug use, trespassing, drunkenness), or even infections and viruses. Safety has been at the forefront of transport planning for more than a decade. However, despite all the attention from politicians, decision-makers, and scholars, there still exists a gap in knowledge on how travel safety perceptions might influence perceptions of accessibility. Perceived accessibility can be defined as "the ease of living a satisfying life (with the help of the transport system [1] (p.36) and refers to the individual perceptions, experiences, and expectations of accessibility. Lättman et al. [1] made an important early contribution to the field by discovering that travel safety perceptions depend on the quality of the service, the higher perceived quality of the service, the safer the travelers felt. The authors also noted that travel safety perceptions explained some of the effects perceived service quality has on the perceived accessibility of public transport. Thus, together with service quality per se, there is reason to believe that travel safety perceptions 
may be an important mediator in our understanding of perceived accessibility. In order to encourage both increased use and further development of existing sustainable transport systems, such as public transport, there exists a need to focus on attributes that have the potential of affecting perceptions of safety and accessibility. Thus, the purpose of the present study was to model the contribution of service quality and travel safety perceptions on the perceived accessibility of public transport travelers. Travel safety perceptions refer to the personal experiences and expectations of safety and security while traveling. This includes the calculated risk of being exposed to hazards as well as affective feelings associated with potential hazards, such as threats from other people (e.g., terrorism, violence, theft, harassments or infections), impacts of accidents (e.g., vehicle accidents, safe waiting areas), discomfort (e.g., a smooth ride quality), and/or fear (e.g., not knowing how to travel, accident, threat). Beecroft and Pangbourne [2] conclude that freedom from potential hazards is equal to high personal security. Service Quality has been highly researched in the past (see, e.g., [3] for an overview), and generally includes different aspects of the travel environment and travel mode(s), such as information, staff behavior, reliability, and comfort. However, to our knowledge, only one previous study [1] has explored the links between different service quality dimensions (e.g., functionality, information, comfort) and travel safety perceptions in the context of public transport, and in relation to perceived accessibility. Thus, more research is needed to establish these relationships.

By addressing this gap in existing research, the current study aims to contribute to the literature in two ways. First, by considering dimensions of service quality within public transport as fundamental determinants of perceived accessibility. Secondly, by showing that travel safety is a significant mediator of the relationship between service quality and perceived accessibility.

In the next section, we develop hypotheses about the influence of service quality on perceived accessibility and the travel safety perceptions' mediating effect. This section is followed by the study research design and a description of our variable measures. We then present the results of an empirical study comprising responses by 4944 public transport users in five European cities, allowing us to test the hypothesized relationships and also conduct city comparisons. We conclude with a discussion of managerial implications, address the limitations of the study, and suggest directions for further research.

\section{Literature Review and Research Hypotheses}

\subsection{Service Quality}

Until the 1990s, transportation research mainly focused on technology development, planning of transport systems, and demand modeling. However, during the 1990s, there was an increase in studies focusing on service quality and user satisfaction [4,5]. It became evident that service quality relates to travel behavior [6]. Thus, the importance of service quality could not be overlooked and several studies have since then, in Europe and other countries, focused on service quality attributes [7-12]. An overview of service quality research presented in 2013 [3] concludes that there are two types of quality attributes: (1) Perceived attributes which refer to direct experiences of the service (e.g., comfort) and (2) physical attributes which need not involve direct experiences of the service (e.g., timekeeping). For evaluating the attractiveness or improving public transport service, it is essential to know the effects of all attributes [3]. Some studies have focused on quality attributes that can attract car drivers [8,13]. The results indicate that shorter travel times, fewer changes, and reliability and frequency of service are basic requirements. Accessibility and price are other important attributes. Users may also demand mobility experiences that are enjoyable and social, not only convenient and efficient. For instance, the opportunity to work while traveling may be important for some, while social interactions may be important for others [14]. Quality attributes reflect different quality dimensions that have, in previous research, varied in nature or content. Although there is no general agreement, the quality of public transport as perceived by the user is often, but not exclusively, related to functionality (reliability, travel time, frequency, distance), information (reliable and timely), and comfort (clean and access to a 
seat). Moreover, the monetary cost of travel, including fare structures and tickets and their validity, is a dimension frequently addressed in research $[15,16]$.

\subsection{Perceived Accessibility}

In the late 1990s, Handy and Niemeier [17] acknowledged that accessibility, in order to be useful in practice, should be based on how individuals perceive their surroundings and evaluate the aspects that are most important to them. However, although Morris, Dumble, and Wigan [18] defined perceived accessibility as a concept already in the 1970s, it did not gain a lot of attention in transport accessibility research until recently $[1,19,20]$. Perceived accessibility refers to the individual dimension of accessibility, in other words, the subjective experiences of the individual's ability to reach preferred destinations and participate in activities of choice. By capturing individual experiences, the concept is related to social consequences, such as social inclusion, transport disadvantage, and transport justice [21,22]. Contrary to many other approaches to accessibility which generally imply that the level of accessibility is the same for everyone living in a specific area and traveling with a specific transport mode (often based on travel times to specific destinations or activities), perceived accessibility is based on individual preferences and prerequisites interacting with the objective transport environment, such as the perceived ability to use public transport to reach preferred activities [23]. These perceptions may differ substantially from conventional accessibility conceptualizations and between individuals [24,25]. Perceived accessibility has been defined as "how easy it is to live a satisfactory life with the help of the transport system" [1] (p.36). The definition includes, but is not restricted to, accessibility in terms of the ease of getting to and using the transport system, and the perceived possibilities of living the life one wants, with the help of (acknowledged) existing transport options. In line with other definitions of accessibility, such as that offered by The Social Exclusion Unit [26] which highlights the ease of access to activities, perceived accessibility depends upon the individual perception of her context and travel opportunities, which may include feelings of safety and security or assessments of transport-related service quality. In fact, Lättman et al. [1] showed that service quality is important for the perceived accessibility of public transport. In their study, an overall service quality evaluation positively contributed to perceived accessibility. When travelers think the service is of a high quality, they also perceive the service as more accessible, making it easier for them to live the life they want.

\subsection{The Role of Travel Safety Perceptions}

Travel safety perceptions mean that travelers are aware and take calculated risks and affective feelings into account when evaluating public transport. Studies exploring travel safety perceptions indicate that certain groups of users adjust their travel behavior to avoid incidents that are perceived as risky and as a threat to personal safety [27]. Vulnerable groups, such as women, older and younger, tend to take travel safety perceptions into account to a greater extent than men. This is shown in studies from many different countries with different transport systems [28-30]. Shortcomings in service quality may explain why users do not feel safe. The driver is often perceived as the person responsible for travelers' safety. For this reason, many complaints and critical incidents are directed at the driver [31,32], even though the driver is not always responsible for the incident. Other examples are unclean and cluttered buses or unreliable timekeeping, leading to extended waiting times in interchanges where the traveler feels exposed and is often left without satisfactory information. Service failures may be perceived as threats to personal safety, although objectively, there may not exist such a danger. Studies of negative critical incidents show how such incidents tend to weigh heavier in an overall assessment of the service [33]. Incidents where the traveler feels afraid and unsafe can thus have a relatively significant impact over time and spill over, not only on the overall assessment of service quality but also on expectations of personal safety. Thus, implicit expectations can be used as cues to assess the risk of being exposed to critical incidents when traveling. When such expectations are violated, these may be particularly salient. A reliable service, where the staff acts professionally in a customer-friendly way, with clean and comfortable vehicles, with waiting areas that are welcoming 
and where the traveler has access to real-time information is assumed to minimize the need to calculate different risks and produce less affective feelings of uncertainty and fear. On the contrary, low service quality likely contributes to increased risk calculations and production of affective feelings related to the concern of personal safety.

\subsection{Research Objective and Hypotheses}

In order to plan for and maintain sustainable transport system that will actually compete with the superiority of the private car, that will be attractive to both current travelers and potential users, and able to offer sufficient levels of accessibility according to the actual users, we need to explore which factors affect perceptions of accessibility. Thus, the main objective of the present study is to explore the determinants of perceived accessibility in public transport, in five European cities.

In line with previous findings suggesting a relationship between service quality dimensions and perceived accessibility [1], we argue that the service quality of public transport can create prerequisites for possibilities and ease of engaging in preferred activities. Hence, we hypothesize that: (H1) Service quality is positively related to perceived accessibility.

Moreover, travel safety perceptions are assumed to play an intermediate role between service quality and perceived accessibility. High service quality may predispose travelers not to activate their travel safety perceptions. Low service quality may, on the contrary, predispose or trigger travelers to activate their travel safety perceptions. Travel safety perceptions will, in turn, relate to people's perceived ease to engage in desirable activities. Thus, we hypothesize that (H2): Travel safety perceptions mediate the relationship between service quality evaluations and perceived accessibility.

Regarding levels of perceived accessibility, travel safety perceptions, and different quality dimensions are likely to vary between contexts, an underlying objective was to explore potential variations between the included study areas (five northern European cities).

\section{Materials and Methods}

\subsection{Procedure and Sample}

The study was based on data collected by BEST (Benchmarking European Service of Public Transport) in collaboration with Norstat, a market research company that complies with international quality standards (ISO 26362 and ISO 9001). The data collection consisted of monthly web surveys combined with structured telephone interviews and was performed during 2018. As the process was continuously monitored, the sample is representative of the general population of the included cities, respectively, regarding the sociodemographic structure (age, gender, and employment status). All procedures were performed in compliance with regulations and institutional guidelines, including appropriate institutional committee approval (C2017/938). The participants were informed about their anonymity, the right to drop out at any time, and gave their consent to participate. Upon completion of the questionnaire, they were offered a small reward (e.g. cinema ticket, lottery ticket, or a charity donation). In the survey, data on perceived accessibility, service quality, sociodemographic data, and travel behavior were collected. Between May and December 2018, 4944 individuals from five northern European cities (Bergen, Copenhagen, Helsinki, Oslo, and Stockholm) participated. The cities included are part of the BEST network and participated in the study due to an interest in assessing perceived accessibility and service quality and the relationship between these concepts. In Table 1 sample descriptives of the five cities are provided. 
Table 1. Sample descriptives across cities.

\begin{tabular}{|c|c|c|c|c|c|}
\hline $\begin{array}{c}\text { City } \\
\text { (Inhabitants in Millions) }\end{array}$ & $\begin{array}{c}\text { Stockholm } \\
\text { (2.3) }\end{array}$ & $\begin{array}{l}\text { Oslo } \\
(1.3)\end{array}$ & $\begin{array}{c}\text { Copenhagen } \\
(2.1)\end{array}$ & $\begin{array}{l}\text { Helsinki } \\
\quad(1.5)\end{array}$ & $\begin{array}{l}\text { Bergen } \\
(0.4)\end{array}$ \\
\hline Number of participants (N) & 1064 & 587 & 619 & 1112 & 1562 \\
\hline Women (\%) & 51.2 & 48.2 & 47.0 & 54.0 & 52.8 \\
\hline Age (mean/sd) & $40.5 / 13.4$ & $38.2 / 13.0$ & $38.5 / 14.1$ & $41.2 / 13.7$ & $42.5 / 13.9$ \\
\hline High car-use (\%) & 42.3 & 47.1 & 39.8 & 65.7 & 78.0 \\
\hline High public transport-use (\%) & 62.5 & 66.7 & 35.1 & 58.5 & 33.9 \\
\hline
\end{tabular}

\subsection{Measures}

Mode use was measured on a scale from 1 to 5 , indicating the degree of use, from (1) never to (5) always. Based on this scale, high vs. low car users (as a driver or as a passenger) were identified, where high car users were categorized as such if they used the car several times a week. The same procedure was used for public transport users, where those using public transport several times a week were categorized as high public transport users and those using public transport more seldom as low public transport users.

Perceived accessibility was measured with the Perceived Accessibility Scale (PAC), developed by Lättman et al. [25,34]. The PAC consists of four statements (items) which the respondent is asked to evaluate on a scale from 1 to 7 ( $1=$ I disagree, $7=$ I completely agree). The items measure the ease of travel, the ability to live the life one wants, access to preferred activities, and satisfaction with access to activities (For the exact phrasing of items, see Table 2).

Table 2. Item description of the Perceived Accessibility Scale (PAC).

\begin{tabular}{cc}
\hline PAC Item & Wording \\
\hline 1 & Considering how I travel today, it's easy to do (daily) activities. \\
2 & Considering how I travel today, I'm able to live my life as I want to. \\
3 & Considering how I travel today, I'm able to do all the activities I like to do. \\
4 & Considering how I travel today, access to my preferred activities is satisfying. \\
\hline
\end{tabular}

Service quality was measured with a number of statements on a scale ranging from 1 to 5 ( $1=$ do not agree, 5 = fully agree). Building upon dimensions identified in previous research $[1,3,10,15,16]$, the statements were categorized into four quality constructs (Table 3).

Perceived travel safety was measured with three statements covering safety at station/bus stop (I feel secure at stations and bus stops), aboard (I feel secure aboard buses and trains), and impacts of accidents ( $\mathrm{I}$ am not afraid of traffic accidents when using public transport) on a scale ranging from 1 to 5 ( 1 = do not agree, 5 = fully agree $)$. 
Table 3. Description of the public transport service quality items included in the questionnaire, sorted according to the corresponding quality construct and travel safety.

\begin{tabular}{|c|c|c|}
\hline Quality Dimension & Label & Item in Questionnaire \\
\hline \multirow{5}{*}{ Functionality } & Travel time & Travel times on public transport are reasonable \\
\hline & Reliability & Public transport mostly runs on schedule \\
\hline & Frequency & I am satisfied with the number of departures \\
\hline & Transfers & Transfers are easy \\
\hline & Closeness & The nearest stop is close to where I live \\
\hline \multirow[t]{2}{*}{ Information } & During critical incidents & $\begin{array}{c}\text { The information provided is good when traffic } \\
\text { problems occur }\end{array}$ \\
\hline & At stops & $\begin{array}{c}\text { The information provided is good at stops } \\
\text { and terminals }\end{array}$ \\
\hline \multirow{4}{*}{ Comfort } & Comfortable & Traveling by public transport is comfortable \\
\hline & Modern & The buses and trains are modern \\
\hline & Clean & The buses and trains are clean \\
\hline & Seat & I normally get a seat when I travel by public transport \\
\hline \multirow{2}{*}{ Cost } & Value & Public transport gives value for money \\
\hline & Price & Public transport fares are reasonable \\
\hline
\end{tabular}

\section{Analyses and Results}

The data analyses were conducted by means of partial least square structural equation modeling (PLS-SEM), using the SmartPLS 3.0 software [35]. PLS-SEM is a robust method that relies on a nonparametric bootstrap procedure (5000 subsamples are recommended) to test estimated path coefficients [36]. Before testing the measurement model, tests of convergent validity, reliability, discriminant validity, model fit, explained variance, and predictive relevance were performed in order to assess the appropriateness of the model and the latent constructs (service quality, safety, and perceived accessibility).

Finally, differences in means between cities for perceived accessibility and each of the four quality constructs, and perceived travel safety were tested by analyses of variance (Anova), followed by Bonferroni corrected pairwise post hoc t-tests.

\subsection{PLS-SEM}

The measurement model to be tested by PLS-SEM is given in Figure 1. As can be seen, and in line with our hypothesis (H1), there are hypothesized direct paths from all four quality constructs and perceived travel safety to PAC. To test for any mediational effects (H2), hypothesized indirect paths to PAC through perceived travel safety are also shown. Age, gender, and frequent car and public transport use are controlled for.

Before reporting model fit, explained variance, predictive relevance and statistical results, the reliability and validity of the latent variables (PAC, Perceived travel safety, Comfort, Cost, Information, and Functionality) were assessed. 


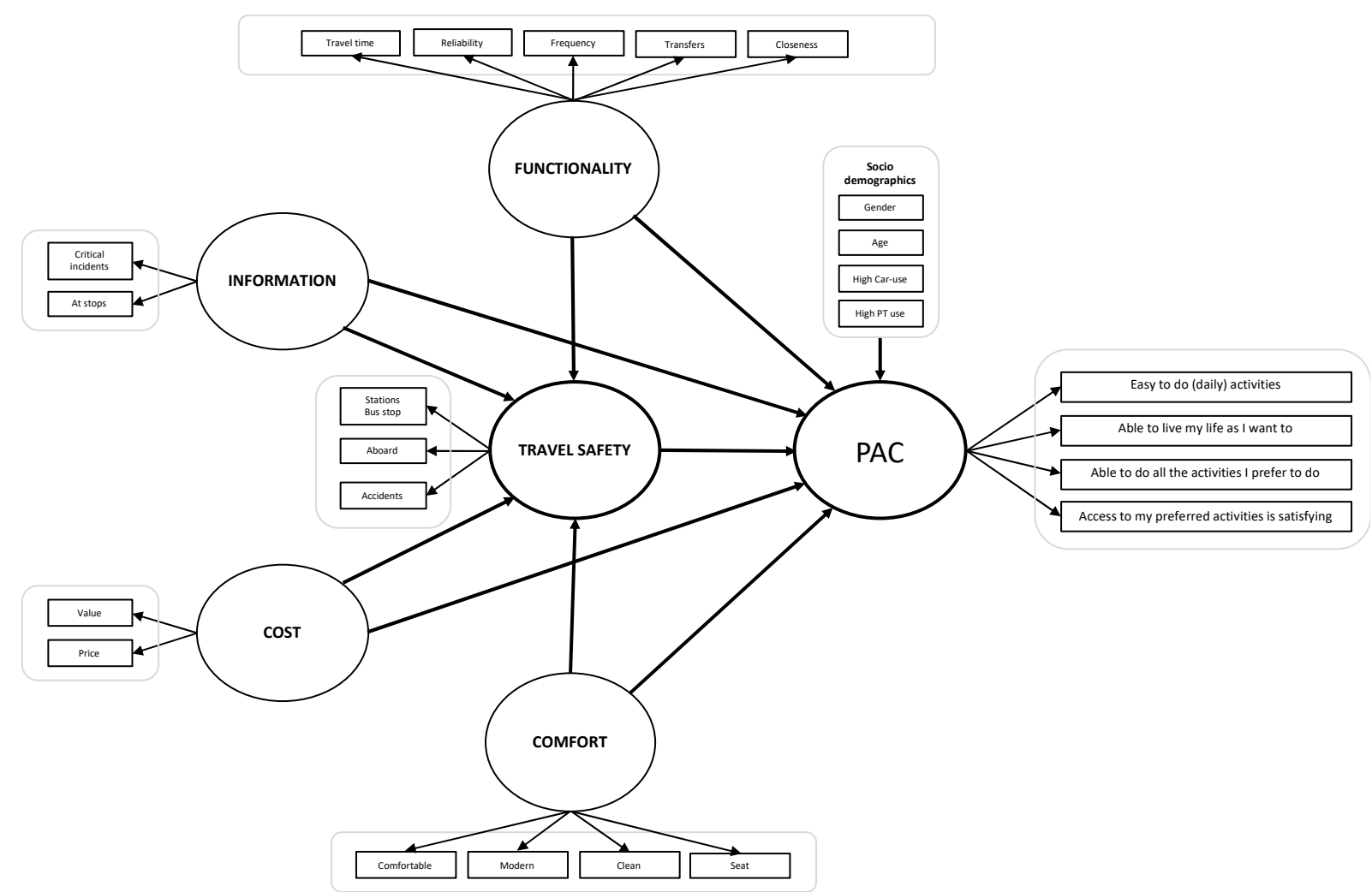

Figure 1. PLS-SEM measurement model of direct and mediated effects of quality and perceived travel safety on perceived accessibility (PAC).

\subsubsection{Reliability and Validity of the Latent Constructs}

To assess discriminant validity among and between the latent constructs, Heterotrait-Monotrait ratio of correlations [HTMT] was calculated. Constructs being below the critical value of 0.85 [37] are judged to have satisfactory discriminant validity. All latent constructs showed satisfactory HTMT, confirming discriminant validity. Convergent validity was then assessed by the average variance extracted (AVE). All constructs had an AVE above the critical value of 0.50 [38], confirming convergent validity. The reliability of the constructs was assessed by composite reliability (CR). All constructs exceeded the recommended critical value of 0.708 [36], yielding construct reliability. The above measures of reliability and validity are displayed in Table 4.

Table 4. Heterotrait-Monotrait ratio of correlations (HTMT), Average variance extracted (AVE), and Composite reliability (CR) for the latent constructs in the model.

\begin{tabular}{cccc}
\hline & HTMT & AVE & CR \\
\hline Perceived Accessibility & $0.10-0.34$ & 0.807 & 0.944 \\
Perceived travel safety & $0.04-0.67$ & 0.726 & 0.888 \\
Functionality & $0.09-0.76$ & 0.592 & 0.878 \\
Comfort & $0.06-0.71$ & 0.611 & 0.862 \\
Information & $0.06-0.76$ & 0.544 & 0.856 \\
Cost & $0.02-0.57$ & 0.873 & 0.932 \\
\hline
\end{tabular}

Note: Variance inflation factors (VIF) were below 3.0, indicating a lack of multi-collinearity between the constructs [36].

\subsubsection{Model fit, Explained Variance, and Predictive Relevance}

Predictive relevance (indicated by the $\mathrm{Q}^{2}$ measure) is a measure of how well PLS-SEM predicts the data points of the indicators. $\mathrm{A} \mathrm{Q}^{2}$ value larger than zero, for a certain latent variable, indicates that 
the PLS path model has predictive relevance for this construct [36]. Predictive relevance was found to be well above the acceptable values for both PAC $\left(Q^{2}=0.14\right)$ and travel safety $\left(Q^{2}=0.23\right)$.

Conventional measures of model fit may not be perfectly suited for PLS-SEM, and there is an ongoing debate about appropriate model fit indices and acceptable threshold values [30]. Since consensus has not yet been reached, we report two model fit indices that were found satisfactory: SRMR, 0.06 (critical value $<0.08$ ), and rms Theta 0.13 (slightly exceeding the threshold value of $<0.12$ ) $[39,40]$. Explained variance was, furthermore, estimated to $R^{2}=0.19$ for $P A C$, and $R^{2}=0.38$ for perceived travel safety. In summary, the proposed model has acceptable reliability, validity, and predictive relevance.

\subsubsection{Structural Model}

Statistical results of the PLS-SEM with respect to direct paths from the latent constructs to PAC can be found in Table 5. Indirect paths via travel safety can be found in Table 6. As can be seen, and in line with our hypotheses, all latent quality constructs had significant paths to PAC, both directly and indirectly, mediated by perceived travel safety, showing that higher quality is positive for PAC $\left(\mathrm{H}^{1}\right)$ and perceived travel safety, in addition, has a mediating role $\left(\mathrm{H}^{2}\right)$, although substantially weaker than the direct effects observed. Although significant, cost and comfort had low path coefficient weights for PAC, whereas functionality had the strongest path. It could also be observed that accessibility increases with age, and that women report greater PAC than men, although the latter had a weak path coefficient. With respect to mode use, we observed that high car use is associated with greater PAC. As indicated by the negative sign for high public transport use, the reverse effect was observed where frequent users perceive their accessibility as worse than those less frequently using public transport.

Table 5. Direct effects in PLS-SEM of the latent quality attributes and perceived accessibility (PAC) and perceived travel safety.

\begin{tabular}{cccc}
\hline & $\mathbf{B}$ & $\mathbf{t}$ & $\boldsymbol{p}$ \\
\hline PERCEIVED ACCESSIBILITY & & \\
\hline Functionality -> PAC & 0.200 & 10.570 & $<0.001$ \\
Age -> PAC & -0.198 & 14.194 & $<0.001$ \\
Public transport high/low -> PAC & 0.105 & 7.525 & $<0.001$ \\
Information -> PAC & 0.079 & 4.287 & $<0.001$ \\
Perceived travel safety -> PAC & 0.077 & 4.232 & $<0.001$ \\
Car use high/low -> PAC & 0.076 & 5.555 & $<0.001$ \\
Comfort -> PAC & 0.047 & 2.397 & 0.017 \\
Women -> PAC & 0.046 & 3.498 & $<0.001$ \\
Cost -> PAC & 0.038 & 2.527 & 0.012 \\
\hline PERCEIVED TRAVEL SAFETY & & \\
\hline Comfort -> Perceived travel safety & 0.291 & 17.761 & $<0.001$ \\
Information -> Perceived Travel safety & 0.286 & 17.157 & $<0.001$ \\
Functionality -> Perceived Travel safety & 0.085 & 5.089 & $<0.001$ \\
Cost -> Perceived Travel safety & 0.039 & 2.804 & 0.005 \\
\hline
\end{tabular}

Table 6. Perceived travel safety as a mediator (indirect effects in PLS-SEM) between the latent quality attributes and perceived accessibility (PAC).

\begin{tabular}{cccc}
\hline & $\boldsymbol{B}$ & $\mathbf{t}$ & $\boldsymbol{p}$ \\
\hline Comfort -> Perceived Travel safety -> PAC & 0.023 & 4.089 & $<0.001$ \\
Information -> Perceived Travel safety -> PAC & 0.022 & 4.067 & $<0.001$ \\
Functionality - > Perceived Travel safety -> PAC & 0.007 & 3.226 & 0.001 \\
Price -> Perceived Travel safety -> PAC & 0.003 & 2.400 & 0.016 \\
\hline
\end{tabular}


The paths from the four quality constructs to perceived travel safety were all significant. However, as can be seen in Table 6, comfort and information were the two constructs of greatest weight, whereas functionality and cost had substantially less weight.

\subsection{City Comparisons}

To assess potential differences between cities regarding the four quality constructs, Perceived travel safety and perceived accessibility, comparisons by means of variance (Anova) were conducted, followed by Bonferroni corrected pairwise post hoc t-tests. In Table 7, means and standard deviations across the five cities are displayed. Although, as can be seen, only small variations in means can be found between the cities, all Anova's yielded significant results $(p<0.001)$, indicating the existence of some variation. Follow-up post hoc test yielded that Stockholm scored significantly lower on $P A C$ than all other cities $(p<0.01)$ except Oslo. As concerning Information, Stockholm scored significantly $(p<0.01)$ lower than all cities but Copenhagen. For Perceived travel safety, three groups can be distinguished, where yet again, Stockholm scores significantly lower than the other cities $(p<0.001)$, Helsinki and Copenhagen can be found in the middle, and Oslo and Bergen with the highest scores $(p<0.01)$. For Comfort $(p<0.01)$ and Cost $(p<0.001)$, Helsinki is the city with significantly higher scores, while on the latter, Copenhagen scores significantly lower than the others $(p<0.01)$. And finally, for Functionality, Oslo was the top city, scoring significantly higher than all other cities $(p<0.01)$.

Table 7. Means and standard deviation of the four quality constructs, Perceived travel safety and perceived accessibility (PAC) across the five cities. Highest mean marked in bold, and lowest mean in italics.

\begin{tabular}{|c|c|c|c|c|c|c|c|c|c|c|c|c|c|}
\hline \multicolumn{2}{|l|}{$\begin{array}{l}\text { Construct } \\
\text { (scale) }\end{array}$} & \multicolumn{2}{|c|}{$\begin{array}{l}\text { PAC } \\
(1-7)\end{array}$} & \multicolumn{2}{|c|}{$\begin{array}{c}\text { Travel Safety } \\
\text { (1-5) }\end{array}$} & \multicolumn{2}{|c|}{$\begin{array}{c}\text { Functionality } \\
(1-5)\end{array}$} & \multicolumn{2}{|c|}{$\begin{array}{c}\text { Information } \\
(1-5)\end{array}$} & \multicolumn{2}{|c|}{$\begin{array}{l}\text { Comfort } \\
\text { (1-5) }\end{array}$} & \multicolumn{2}{|c|}{$\begin{array}{l}\text { Cost } \\
(1-5)\end{array}$} \\
\hline City & $\mathrm{N}$ & Mean & $\begin{array}{l}\text { Std. } \\
\text { Dev. }\end{array}$ & Mean & $\begin{array}{l}\text { Std. } \\
\text { Dev. }\end{array}$ & Mean & $\begin{array}{l}\text { Std. } \\
\text { Dev. }\end{array}$ & Mean & $\begin{array}{l}\text { Std. } \\
\text { Dev. }\end{array}$ & Mean & $\begin{array}{l}\text { Std. } \\
\text { Dev. }\end{array}$ & Mean & $\begin{array}{l}\text { Std. } \\
\text { Dev. }\end{array}$ \\
\hline Stockholm & 1064 & 5.09 & 1.32 & 3.73 & 0.85 & 3.65 & 0.76 & 2.93 & 1.01 & 3.43 & 0.78 & 2.71 & 1.24 \\
\hline Oslo & 587 & 5.17 & 1.36 & 4.18 & 0.89 & 3.88 & 0.83 & 3.19 & 1.08 & 3.54 & 0.89 & 2.86 & 1.20 \\
\hline Helsinki & 1112 & 5.36 & 1.13 & 3.93 & 0.83 & 3.72 & 0.81 & 3.16 & 1.05 & 3.84 & 0.72 & 3.25 & 1.14 \\
\hline Copenhagen & 619 & 5.35 & 1.32 & 3.99 & 0.92 & 3.67 & 0.80 & 3.03 & 1.06 & 3.43 & 0.82 & 2.46 & 1.12 \\
\hline Bergen & 1562 & 5.42 & 1.41 & 4.20 & 0.88 & 3.59 & 0.88 & 3.07 & 1.14 & 3.71 & 0.85 & 2.84 & 1.22 \\
\hline
\end{tabular}

\section{Discussion}

Although service quality is a vastly researched area in transportation, this study is one of the first to explore the links between public transport service quality, travel safety perceptions, and the perceived accessibility of daily travel. Accessibility is important in its role as a prerequisite for actual travel, thus knowledge of the relationship between different service quality attributes and travel safety perceptions and their influence on perceived accessibility is crucial when focus lies on improving the service and safety of public transport systems aiming for increased accessibility.

\subsection{General Findings in Light of the Structural Model and the Hypotheses}

As hypothesized, service quality appears to be positively related to perceived accessibility, with some service quality dimensions contributing more than others to this relationship. Thus, when valued as high-quality, the included service dimensions (functionality, information, comfort, and cost) are likely to create prerequisites for perceiving the service as accessible. Functionality was found to be the most influential quality dimension, followed by information and comfort. Functionality includes aspects such as reasonable travel times, reliability, frequency, easy transfers, and closeness to the nearest public transport stop. These results are not surprising as travel time, reliability and frequency are service aspects that are generally linked to accessibility, and frequency of service has previously been linked to the traveler experience of accessibility [1]. However, interestingly, cost was the service attribute least important for perceived accessibility, indicating that although cost is generally perceived 
as an attribute of overall importance for accessibility together with functionality [41], when individuals evaluate their own accessibility, public transport cost appears of less importance than other quality attributes, and also less important than travel safety perceptions. A plausible reason for this may be that public transport cost is of greater importance in specific contexts (this study only includes prosperous northern European cities), and for certain groups of individuals (low-income).

The results are somewhat in line with previous findings [1] in that functionality appears to be the service quality dimension most important for perceived accessibility. However, in this study, information was found to have a higher impact on perceived accessibility than in the previous study. A possible explanation for this discrepancy may lie in that the Lättman et al. [1] study mainly included frequent (bus) travelers, whereas the current study includes both frequent and less frequent travelers (of different public transport modes). Thus, there is a possibility that frequent travelers are less concerned with travel information (as they know the routes and routines of the system), whereas individuals using public transport less frequently are in greater need of adequate information in order to experience adequate accessibility. In fact, bearing in mind the close link between accessibility and social inclusion [42], the findings may well have implications for future research on identifying the service quality attributes that will have the greatest influence on building inclusive and sustainable transport systems with the needs and preferences of both frequent and less frequent public transport travelers in mind.

When looking at the links between the concepts of service quality and travel safety perceptions, all service quality dimensions were significantly linked to perceived travel safety, and indirectly to perceived accessibility. However, comfort and information were the two quality dimensions with the strongest links to travel safety perceptions, indicating that the experience of high comfort and good levels of information are of importance for both travel safety perceptions per se, but also for perceived accessibility directly and through the influence of safety perceptions. Thus, well-informed and comfortable travelers appear to feel both safer, and accordingly, also perceive their accessibility as better. On the contrary, as hypothesized, low-quality information and low comfort are likely to contribute to increased risk calculations and affective feelings related to personal safety concerns, which, both directly and indirectly, affects perceptions of accessibility. These relationships may be explained by aspects such as available seating (minimizes risks of falling), adequate information at critical incidents, stops, and terminals (minimizes risks of not knowing what to do or miss a connecting transport), or modern and clean interiors (as opposed to broken, trashed interiors, and lack of cleaning). Contrary to other findings [25] where no age differences for perceived accessibility were detected, we found that perceived accessibility increases with age for our sample. A possible explanation for increased perceived accessibility among elderly age groups, despite the age-related decline in physical prerequisites for easy travel, is offered by Lättman et al. [43] and poses that the elderly travel less and to fewer destinations than younger people do, and thus are less dependent on transport systems. Our findings, and recent findings among other researchers [20], imply though that subjective factors, such as attitudes and functionality, may be better predictors of perceived accessibility than sociodemographic factors, such as age.

In line with recent research [44] which concluded that more frequent travel with public transport (than desired) may negatively impact attitudes and satisfaction, the present results suggest that the frequency of public transport travel also appears to have a negative impact on perceived accessibility. Thus, individuals traveling more frequently with public transport also experience their accessibility as lower than people who travel less often. An interesting question arising from this is how low perceptions of accessibility can get before individuals feel that they need to change their mode of travel, or if it is more likely that these individuals already have or will adapt to the situation and accept lower levels of accessibility. As car use still appears to be relatively high even when public transport use is high in our sample, it is important to raise the question of what will happen in these contexts if individuals are starting to be dependent to an even larger share of public transport use for their daily travel. For instance, a study in Malmö, Sweden [45] showed that a restricted car use scenario 
(no private car use) significantly affected levels of perceived accessibility even for individuals that do not use the car on a daily basis today but only for specific destinations and activities. In such a scenario, there is a need to lift those attributes that are important to public transport-related perceived accessibility, such as quality aspects and travel safety perceptions, in order to maintain a level of perceived accessibility that offers satisfactory possibilities to engage in daily activities. In any case, as perceived accessibility recently has been linked to life satisfaction [43], it appears important not only to examine the role of perceptions of accessibility for modal choice but to also further explore the effect of modal choice on perceived accessibility.

\subsection{Discussion in Relation to City Comparisons}

The city comparisons yielded several significant differences in mean levels of service quality, travel safety perceptions, and perceived accessibility. These differences mainly lie in that some cities stand out in one direction, and others in another direction, without any clear indication of systematic differences based on the data included in the present study. However, on a theoretical level, there exist a number of possible explanatory factors for these differences. For one, there is a possibility that interventions aiming at reducing car-use (such as reduced parking opportunities or city tolls) have had an impact on the differences in experiences of different service quality dimensions and perceived accessibility when individuals are forced to use a less preferred mode of travel. It is also possible that city sizes and/or presence of crime and criminality affect travel safety perceptions and, in turn, perceptions of accessibility. Other aspects of interest are the objective quality of the transport system and objective accessibility conditions, alongside possible attitudinal and cultural differences. However, as this study offers no evidence for any of these interpretations, they need to be analyzed and confirmed in future studies.

\subsection{Policy Relevance}

With better knowledge of service quality, perceived accessibility, and safety, it is possible to develop an attractive public transport with increased economic viability. It is well known that the attractiveness of the service influences people's attitudes towards the service. A positive attitude and increased public transport accessibility increase the likelihood of switching behavior from car to public transport, frequency of use, loyalty, and positive word-of-mouth [46]. However, an improved service quality and increased accessibility drive costs. For economic viability, it is thus important to balance supply and demand. Börjesson and Friman [47] show how supply has increased faster than demand in Sweden, which has led to Sweden having experienced declining cost efficiency in the public transport sector. Investments in supply are necessary as they will improve the functionality of public transport with, among other things, shorter waiting times and shorter travel times. However, we would also like to underline the importance of contextual adoptions for economic sustainability. For instance, the choice of vehicle fleet could very well vary depending on density and built environment but still result in high service quality and perceived accessibility. Based on our findings, we would recommend continuously long-term quality work focusing on user experiences.

Following the previous argument, in a changing world, how important are quality and safety aspects when options of alternatives to public transport diminish in line with new policies and regulations toward a larger share of sustainable travel? Results can guide practitioners into which aspects of quality are related to how individuals perceive their possibilities to reach activities and participate in daily activities. If safety is a concern, and the quality, in particular functionality and information, is low, there is a risk that individuals avoid certain activities and become at risk of being socially excluded and experience lower quality of life. In the face of Covid-19, we now witness increasing safety concerns of using public transport, which for some groups, may have a negative effect on the possibilities to participate in social activities. 


\subsection{Limitations and Future Research}

All studies have some limitations. We particularly want to highlight the choice of included cities. Although being different in levels of the included accessibility, service quality, and safety measures, they are still contextually similar regarding population structures, geographical conditions. such as weather, and political and cultural commonalities. Future studies should include cities from other parts of the world, and may also preferably include other contexts than urban areas to get a better understanding of different determinants of perceived accessibility depending on various settings and prerequisites for travel. We also want to highlight the choice of quality dimensions. It may be worthwhile in future studies to include more dimensions in order to get a complete picture of what quality aspects are important for travel safety perceptions and perceived accessibility. We speculate on the importance of cost, thus different income-groups could be considered in future studies. Finally, perceived accessibility was measured in general, thus not aimed at assessing a specific mode. This means that, for some individuals (high public transport use), quality and travel safety is likely to play a much bigger role, than for those who have the option of using other modes for their daily activities. Future studies may take these limitations into account. With regard to other proposals for future research, we have presented some suggestions in light of our findings in Sections 5.1 and 5.2.

\section{Conclusions}

In order to encourage both the use and further development of a sustainable transport system, we need to focus on making public transport safe and accessible to everyone. As public transport in itself is inevitably less accessible than door-to-door options for travel, it is important to emphasize a focus on the attributes that are related to people's perceived ease of living the life they want with help of the (sustainable) transport system, e.g., their perceived accessibility. Our findings highlight the importance of service quality and travel safety perceptions for perceived accessibility in daily travel. More specifically, we argue that functionality is the core attribute to focus on and that attributes related to travel safety perceptions, such as information and comfort, should also be carefully considered. Based on our research, we conclude that economic development, social development, and environmental protection require an acknowledgment of current and potential users to a greater extent, alongside the context. In the development of future public transport, there is a need to embrace a long-term perspective, including continuous quality improvements adopted to contextual requirements.

Author Contributions: Idea, conceptualization and methodology, M.F., K.L., and L.E.O.; formal analysis and interpretation, L.E.O., M.F., K.L.; writing—original draft preparation, K.L., M.F., L.E.O.; writing一review and editing, K.L., M.F., L.E.O.; funding acquisition, L.E.O., M.F., K.L. All authors have read and agreed to the published version of the manuscript. All authors contributed substantially.

Funding: This research was funded by the Swedish Energy Agency (SWEA), grant No. 46918-1.

Conflicts of Interest: The authors declare no conflict of interest. The funders had no role in the design of the study; in the collection, analyses, or interpretation of data; in the writing of the manuscript, or in the decision to publish the results.

\section{References}

1. Lättman, K.; Friman, M.; Olsson, L.E. Perceived Accessibility of Public Transport as a Potential Indicator of Social Inclusion. Soc. Incl. 2016, 4, 36-45. [CrossRef]

2. Beecroft, M.; Pangbourne, K. Future prospects for personal security in travel by public transport. Transp. Plan. Technol. 2015, 38, 131-148. [CrossRef]

3. Redman, L.; Friman, M.; Gärling, T.; Hartig, T. Quality attributes of public transport that attract car users: A research review. Transp. Policy 2013, 25, 119-127. [CrossRef]

4. Andreassen, T.W. (Dis) satisfaction with public services: The case of public transportation. J. Serv. Mark. 1995, 9, 30-41. [CrossRef]

5. Murugesan, R.; Moorthy, N.R. Level of public transport service evaluation: A fuzzy set approach. J. Adv. Transp. 1998, 32, 216-240. [CrossRef] 
6. Goodwin, P.B. Car ownership and public transport use: Revisiting the interaction. Transportation 1993, 20, 21-33. [CrossRef]

7. Barabino, B.; Deiana, E.; Tilocca, P. Measuring service quality in urban bus transport: A modified SERVQUAL approach. Int. J. Qual. Serv. Sci. 2012, 4, 238-252. [CrossRef]

8. Beirão, G.; Cabral, J.S. Understanding attitudes towards public transport and private car: A qualitative study. Transp. Policy 2007, 14, 478-489. [CrossRef]

9. Cantwell, M.; Caulfield, B.; O'Mahony, M. Examining the factors that impact public transport commuting satisfaction. J. Public Transp. 2009, 12, 1. [CrossRef]

10. Eboli, L.; Mazzulla, G. A new customer satisfaction index for evaluating transit service quality. J. Public Transp. 2009, 12, 21-37. [CrossRef]

11. Friman, M.; Fellesson, M. Service supply and customer satisfaction in public transportation: The quality paradox. J. Public Transp. 2009, 12, 57-69. [CrossRef]

12. Hensher, D.A.; Mulley, C.; Yahya, N. Passenger experience with quality-enhanced bus service: The tyne and wear 'superoute' services. Transportation 2010, 37, 239-256. [CrossRef]

13. Eriksson, L.; Friman, M.; Gärling, T. Stated reasons for reducing work-commute by car. Transp. Res. Part F Traffic Psychol. Behav. 2008, 11, 427-433. [CrossRef]

14. Ettema, D.; Friman, M.; Gärling, T. How in-vehicle activities affect work commuters' satisfaction with public transport. J. Transp. Geogr. 2012, 24, 215-222. [CrossRef]

15. Hensher, D.A.; Stopher, P.; Bullock, P. Service quality-Developing a service quality index in the provision of commercial bus contracts. Transp. Res. Part A 2003, 37, 499-517. [CrossRef]

16. Eboli, L.; Mazzulla, G. A stated preference experiment for measuring service quality in public transport. Transp. Plan. Technol. 2008, 31, 509-523. [CrossRef]

17. Handy, S.L.; Niemeier, D.A. Measuring accessibility: An exploration of issues and alternatives. Environ. Plan. A 1997, 29, 1175-1194. [CrossRef]

18. Morris, J.M.; Dumble, P.L.; Wigan, M.R. Accessibility indicators for transport planning. Transp. Res. Part A Gen. 1979, 13, 91-109. [CrossRef]

19. Wong, S. The limitations of using activity space measurements for representing the mobilities of individuals with visual impairment: A mixed methods case study in the San Francisco Bay Area. J. Transp. Geogr. 2018, 66, 300-308. [CrossRef]

20. Van der Vlugt, A.L.; Curl, A.; Wittowsky, D. What about the people? Developing measures of perceived accessibility from case studies in Germany and the UK. Appl. Mobilities 2019, 4, 142-162. [CrossRef]

21. Martens, K. Transport Justice: Designing Fair Transportation Systems; Routledge: Abingdon, UK, 2016.

22. Schwanen, T.; Lucas, K.; Akyelken, N.; Solsona, D.C.; Carrasco, J.A.; Neutens, T. Rethinking the links between social exclusion and transport disadvantage through the lens of social capital. Transp. Res. Part A Policy Pract. 2015, 74, 123-135. [CrossRef]

23. Ryan, J.; Wretstrand, A.; Schmidt, S.M. Exploring public transport as an element of older persons' mobility: A Capability Approach perspective. J. Transp. Geogr. 2015, 48, 105-114. [CrossRef]

24. Ryan, M.; Lin, T.G.; Xia, J.C.; Robinson, T. Comparison of perceived and measured accessibility between different age groups and travel modes at Greenwood Station, Perth, Australia. Eur. J. Transp. Infrastruct. Res. 2016, 16. [CrossRef]

25. Lättman, K.; Olsson, L.E.; Friman, M. A new approach to accessibility-Examining perceived accessibility in contrast to objectively measured accessibility in daily travel. Res. Transp. Econ. 2018, 69, 501-511. [CrossRef]

26. The Social Exclusion Unit. Making the Connections: Transport and Social Exclusion; ODPM Publications: London, UK, 2004.

27. Loukaitou-Sideris, A. Fear and safety in transit environments from the women's perspective. Secur. J. 2014, 27, 242-256. [CrossRef]

28. Abenoza, R.F.; Ceccato, V.; Susilo, Y.O.; Cats, O. Individual, travel, and bus stop characteristics influencing travelers' safety perceptions. Transp. Res. Rec. 2018, 2672, 19-28. [CrossRef]

29. Yavuz, N.; Welch, E.W. Addressing fear of crime in public space: Gender differences in reaction to safety measures in train transit. Urban Stud. 2010, 47, 2491-2515. [CrossRef]

30. Vanier, C.; de Jubainville, H.D.A. Feeling unsafe in public transportation: A profile analysis of female users in the Parisian region. Crime Prev. Community Saf. 2017, 19, 251-263. [CrossRef] 
31. Friman, M.; Gärling, T. Frequency of negative critical incidents and satisfaction with public transport services. II. J. Retail. Consum. Serv. 2001, 8, 105-114. [CrossRef]

32. Friman, M.; Edvardsson, B. A content analysis of complaints and compliments. Manag. Serv. Qual. 2003, 13, 20-26. [CrossRef]

33. Pedersen, T.; Friman, M.; Kristensson, P. The role of predicted, on-line experienced and remembered satisfaction in current choice to use public transport services. J. Retail. Consum. Serv. 2011, 18, 471-475. [CrossRef]

34. Lättman, K.; Olsson, L.E.; Friman, M. Development and test of the Perceived Accessibility Scale (PAC) in public transport. J. Transp. Geogr. 2016, 54, 257-263. [CrossRef]

35. Ringle, C.M.; Sarstedt, M.; Mitchell, R.; Gudergan, S.P. Partial least squares structural equation modeling in HRM research. Int. J. Hum. Resour. Manag. 2018, 1-27. [CrossRef]

36. Hair, J.F., Jr.; Sarstedt, M.; Ringle, C.M.; Gudergan, S.P. Advanced Issues in Partial Least Squares Structural Equation Modeling; Sage Publications: Thousand Oaks, CA, USA, 2017.

37. Henseler, J.; Ringle, C.M.; Sarstedt, M. A new criterion for assessing discriminant validity in variance-based structural equation modeling. J. Acad. Mark. Sci. 2015, 43, 115-135. [CrossRef]

38. Fornell, C.; Larcker, D.F. Evaluating structural equation models with unobservable variables and measurement error. J. Mark. Res. 1981, 18, 39-50. [CrossRef]

39. Hu, L.T.; Bentler, P.M. Cutoff criteria for fit indexes in covariance structure analysis: Conventional criteria versus new alternatives. Struct. Equ. Model. A Multidiscip. J. 1999, 6, 1-55. [CrossRef]

40. Henseler, J.; Hubona, G.; Ray, P.A. Using PLS path modeling in new technology research: Updated guidelines. Ind. Manag. Data Syst. 2016, 116, 2-20. [CrossRef]

41. Hui, V.; Habib, K.N. An investigation of transport-related social exclusion of the at-risk community in Toronto, Canada. In Proceedings of the Transportation Research Board 93rd Annual Meeting, Washington, DC, USA, 12-16 January 2014.

42. De Oña, J.; Estévez, E.; de Oña, R. Perception of public transport quality of service among regular private vehicle users in Madrid, Spain. Transp. Res. Rec. 2020, 2674, 213-224. [CrossRef]

43. Lättman, K.; Olsson, L.E.; Friman, M.; Fujii, S. Perceived accessibility, satisfaction with travel and life satisfaction among the elderly. Int. J. Environ. Res. Public Health 2019, 16, 4498. [CrossRef]

44. De Vos, J.; Waygood, E.O.D.; Letarte, L. Modeling the desire for using public transport. Travel Behav. Soc. 2020, 19, 90-98. [CrossRef]

45. Lättman, K.; Friman, M.; Olsson, L.E. Restricted car-use and perceived accessibility. Transp. Res. Part D Transp. Environ. 2020, 78, 102213. [CrossRef]

46. Gärling, T.; Bamberg, S.; Friman, M. The role of attitude in choice of travel, satisfaction with travel, and change to sustainable travel. In Handbook of Attitudes, Volume 2: Applications; Routledge: Abingdon, UK, 2018; pp. 562-586.

47. Börjesson, M.; Friman, M.; Fadaei, M. How to make bus systems attractive? In Handbook in Public Transport; Currie, G., Ed.; Edward Elgar Publishing: Cheltenham, UK, 2020.

(C) 2020 by the authors. Licensee MDPI, Basel, Switzerland. This article is an open access article distributed under the terms and conditions of the Creative Commons Attribution (CC BY) license (http://creativecommons.org/licenses/by/4.0/). 